\title{
Heat and Momentum Transfer Analogies for the Transitional and Turbulent Flow of a Non-Newtonian Power-Law Fluid in a Heated
}

Pipe

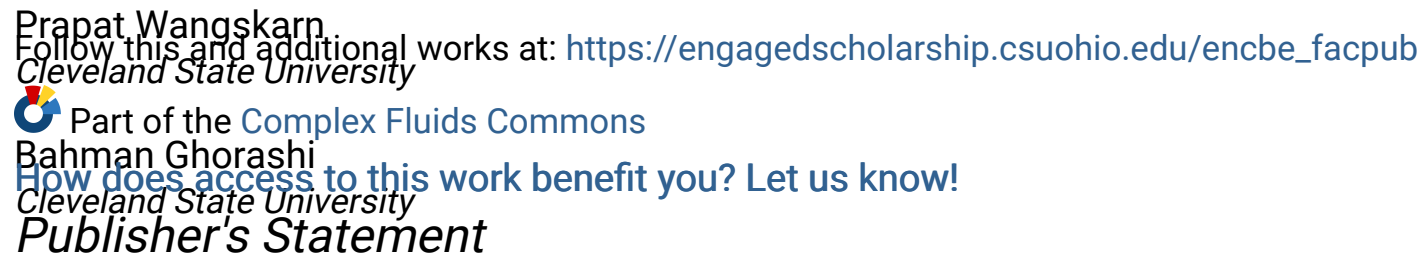

NOTICE: this is the author's version of a work that was accepted for publication in International Communications in Heat and Mass Transfer. Changes resulting from the publishing process, such as peer review, editing, corrections, structural formatting, and other quality control mechanisms may not be reflected in this document. Changes may have been made to this work since it was submitted for publication. A definitive version was subsequently published in International Communications in Heat and Mass Transfer, 17, 2, (March 1990)] DOI 10.1016/ 0735-1933(90)90051-K

\section{Original Citation}

Wangskarn, P., , \& Ghorashi, B. (1990). Heat and momentum transfer analogies for the transitional and turbulent flow of a non-Newtonian power-law fluid in a heated pipe. International Communications in Heat and Mass Transfer, 17(2), 167-178. doi:10.1016/0735-1933(90)90051-K

\section{Repository Citation}

Wangskarn, Prapat and Ghorashi, Bahman, "Heat and Momentum Transfer Analogies for the Transitional and Turbulent Flow of a Non-Newtonian Power-Law Fluid in a Heated Pipe" (1990). Chemical \& Biomedical Engineering Faculty Publications. 60.

https://engagedscholarship.csuohio.edu/encbe_facpub/60

This Article is brought to you for free and open access by the Chemical \& Biomedical Engineering Department at EngagedScholarship@CSU. It has been accepted for inclusion in Chemical \& Biomedical Engineering Faculty Publications by an authorized administrator of EngagedScholarship@CSU. For more information, please contact library.es@csuohio.edu. 
HEAT AND MOMENTUM TRANSFER ANALOGIES FOR THE TRANSITIONAL AND TURBULENT FLOW OF A NON-NEWTONIAN POWER-LAW FLUID IN A HEATED PIPE

P. Wangskarn and B. Ghorashi

ABSTRACT

A model is proposed for the transfer of heat to non-Newtonian powerlaw fluids flowing in heated horizontal pipes. Comparisons with the existing models, based on the absolute-percent-arithmetic-averagedeviation and the percent-standard-deviation, show that under the transitional and turbulent flow regimes the proposed correlation fits the experimental data more accurately over a wide range of flow behavior index and there are no restrictions for its use when applied to pseudoplastic fluids.

\section{Introduction}

Most industrial fluids such as molten polymers, and pharmaceutical materials exhibit a non-Newtonian behavior. A better understanding of the basic heat transfer characteristics of these fluids will lead to more accurate design specification for heat exchange processes. Empirical equations are reported in the literature which provide accurate predictions of heat transfer to such fluids, however, these equations are restricted for use within a given range of Reynolds number and flow behavior index, beyond which they lose their accuracy. The scope of this work was to present a more accurate correlation which would be applicable over a broader range of flow behavior index and Reynolds number. Therefore, a model is proposed for heat transfer to non-Newtonian fluids flowing in heated horizontal pipes. This method is an extension of the proposition by Bouge and Metzner [1] which suggests that the velocity profile of non-Newtonian fluids would be the same as those of Newtonian fluids, when compared on the basis of mean velocity or 
friction velocity. As such, one can apply the Newtonian eddy viscosity profile to explain the case of non-Newtonians. Our proposed correlation separates the flow into two regions, wall region and the outer region, following the suggestions that were made by Clapp [2].

Dodge and Metzner [3] have presented a correlation for predicting the friction factor for purely viscous non-Newtonian fluids. Their general formula for friction factor is an extension of the work by Millikan [4] who investigated Newtonian fluids. Dodge and Metzner applied Millikan's results to non-Newtonian fluids and used the Ostwald-dewaele model to describe the non-Newtonian behavior. Their correlation was as follows:

$$
\frac{1}{\sqrt{f}}-\frac{4.0}{\left(n^{\prime}\right)^{0.75}} \log \left(N_{\operatorname{Re}} f^{1-n^{\prime} / 2}\right)-\frac{0.4}{n^{\prime 1.2}}
$$

Additionally, Metzner and Friend [5] extended the Reichardt analogy to non-Newtonian fluids for the case of heat transfer to carbopol-water, corn syrup and attagel clay solutions. They proposed the following equation for the Stanton number:

$$
\mathrm{N}_{\mathrm{St}}=\frac{\mathrm{f} / 2}{1.20+11.8(\mathrm{f} / 2)^{1 / 2}\left(\mathrm{~N}_{\left.\mathrm{Pr}_{\mathrm{w}}^{\prime}-1\right) \mathrm{N}_{\mathrm{Pr}_{\mathrm{w}}}{ }^{0}{ }^{33}}\right.}
$$

which is subject to the following restriction:

$$
\frac{\mathrm{N}_{\mathrm{Re}}{ } \mathrm{N}_{\mathrm{Pr}}(\mathrm{f} / 2)^{1 / 2}}{\left(\mathrm{n}^{\prime}\right)^{0.25}}>5000
$$

Later, Petersen and Christiansen [6] extended the Metzner-Friend correlation to non-isothermal and transitional flow. The authors claimed an improvement in the prediction of heat transfer if the Prandtl number was modified as follows:

$$
\mathrm{N}_{\mathrm{Pr}_{c}}=\frac{808(n+2)^{(n+2) /(n+1)}}{1050(3 n+1)} \mathrm{N}_{\operatorname{Pr}_{\mathrm{W}}}
$$

In a different study, Clapp [2] conducted an experimental investigation of the non-Newtonian effects on the heat transfer in the range of flow behavior index, 0.69-0.79. Clapp also extended the Karman-Martinelli analogy to purely viscous non-Newtonian fluids and conducted measurements of the velocity distribution of the viscous non-Newtonian fluids in the turbulent core, however measurements were not obtained in the buffer zone and viscous sublayer. Clapp proposed three layers: 


$$
\begin{array}{lr}
\text { Viscous sublayer: } u^{+}=y^{+1 / n} & 0<y^{+}<5^{n} \\
\text { Buffer layer: } u^{+}-\frac{5.0}{n_{2}} \ln y^{+}-3.05 & 5^{n}<y^{+}<y_{2}^{+} \\
\text {Turbulent core: } u^{+}=\frac{2.78}{n} \ln y^{+}+\frac{3.8}{n} & y^{+}>y_{2}^{+}
\end{array}
$$

Yoo and Hartnett [7] collected experimental data over a broader range of the following parameters, $\left(3,000<\mathrm{N}_{\mathrm{Re}^{\prime}}<60,000\right) ;\left(15<\mathrm{N}_{\mathrm{Pr}^{\prime}}<165\right) ;(0.24<$ $n<1.00)$. They concluded that no available method was capable of predicting accurate values of the Nusselt number over a wide range of $n$. Their correlation, shown below, predicts results within $\pm 20 \%$ of experimental data and a broader range of flow behavior index. The restriction is a $\mathrm{N}_{\mathrm{Re}}$ ' greater than 10,000:

$$
\mathrm{N}_{\mathrm{Nu}}=\frac{0.0118}{\mathrm{n}^{\prime}} \mathrm{N}_{\mathrm{Re}}^{0.9} \mathrm{~N}_{\mathrm{Pr}}^{0.3}
$$

Smith and Edwards [8] extended the eddy viscosity expression for Newtonian pipe flow to non-Newtonian flow by using the apparent viscosity at the wall, as suggested earlier by Bouge and Metzner [1]. They concluded that the use of apparent viscosity at the wall was preferable to the method suggested by Dodge and Metzner [3]. Krantz and Wasan [9] presented a correlation which describes heat, mass and momentum transfer in the fully developed turbulent flow of power law fluids in circular tubes. The KrantzWasan formulation has the same form as the Metzner and Friend correlation and also requires a prior knowledge of the friction factor. However, the resulting expression for the Stanton number differs from that of the Metzner and Friend's in that it is based on a continuous eddy viscosity distribution as presented earlier by Wasan, et al. [10]. In their work, the authors extend Wasan's earlier results to non-Newtonian fluids from the wall to the center of the pipe. Numerical integration was required in order to evaluate the Stanton number.

Later, Sandall et al. [11] proposed a new equation which separates the flow into two regions. Their equation, which is entirely different from Metzner and Friend's correlation, also requires a prior knowledge of the friction factor. However, it contains no adjustable parameters like the one suggested by Krantz and Wasan [9]. The authors report that their proposed equation predicts results that are as good as those suggested by Metzner and Friend [5]. 
For a fully developed turbulent pipe flow, heat transfer occurs via both eddy and molecular transport mechanisms. In case of molecular transport of a non-Newtonian power-law fluid, the general shear stress equation at a plane parallel to the wall and the heat flux across this plane, in a dimensiontess form, are as follows, $[3,9]$ :

$$
\begin{aligned}
& \frac{{ }^{\tau} \mathrm{yx}}{\rho}=\left\{\frac{\varepsilon \nu}{\nu}+\phi\left(\frac{\mathrm{du}^{+}}{\mathrm{dy}^{+}}\right)^{\mathrm{n}-1}\right\} \frac{\mathrm{U}_{\star}}{\phi} \frac{\mathrm{dU}^{+}}{\mathrm{dy}} \\
& \mathrm{q}=\rho \mathrm{C}_{\mathrm{p}}\left(\frac{c_{\mathrm{c}}}{\nu}+\frac{1}{\mathrm{~N}_{\mathrm{Pr}},}\right) \frac{\mathrm{U}_{*}}{\phi} \frac{\mathrm{dT}^{+}}{\mathrm{dy}^{+}}
\end{aligned}
$$

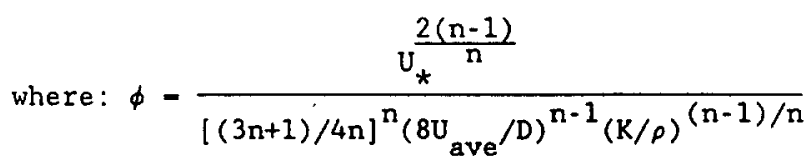

$$
\begin{aligned}
& -\frac{1}{\left(\frac{3 n+1}{4 n}\right)}
\end{aligned}
$$

Dividing equation (10) by (9) and integrating from the center of the tube to the outer edge of the transition region:

$$
\frac{\rho q}{\tau_{y x}}=\frac{\rho q_{W}}{\tau_{w}}=\frac{\left(T_{\text {ave }}-T_{1}\right) \rho C_{p}}{U_{\text {ave }}-U_{1}}
$$

and further integrating equation (9) from the wall to the outer edge of the transition region (two layer approach), using the power-law equation, one would obtain the following:

$$
\begin{aligned}
U_{1}-U_{w} & =\frac{T_{w}}{U_{*} \rho}\left\{\int_{0}^{y_{c}^{+}} \frac{d y^{+}}{\frac{\varepsilon_{\nu}}{\nu \phi}+\left(\frac{d^{+}}{d y^{+}}\right)^{n-1}}+\int_{y_{c}^{+}}^{y_{1}^{+}} f_{1} \frac{d^{+}}{\left.\frac{\varepsilon_{\nu}}{\nu \phi}+\left(\frac{d U^{+}}{d y^{+}}\right)^{n-1}\right\}}\right. \\
\text { where: } f_{1} & =1-\frac{y^{+}}{R^{+}} \\
& =1-\frac{2 y^{+}}{8^{(n-1) / n}}\left(\frac{4 n}{3 n+1}\right)\left(\frac{2}{f}\right)^{(2-n) / 2 n}\left(\frac{1}{N_{R e^{\prime}}}\right)^{1 / n}
\end{aligned}
$$


Substituting equation (13) into equation (12) and rearranging:

$$
\begin{gathered}
T_{\text {ave }}-T_{1}=\frac{\mathrm{q}_{\mathrm{w}} \mathrm{U}_{\text {ave }}}{C_{\mathrm{p}^{\top} \mathrm{w}}}\left[1=\left(\frac{\mathrm{f}}{2}\right)^{1 / 2}\left\{\int_{0}^{\mathrm{y}_{\mathrm{c}}^{+}} \frac{\mathrm{dy}^{+}}{\frac{\varepsilon_{\nu}}{\nu \phi}+\left(\frac{\mathrm{dU}^{+}}{\mathrm{dy} y^{+}}\right)^{\mathrm{n}-1}}\right.\right. \\
+\int_{\mathrm{y}_{\mathrm{c}}^{+}}^{\mathrm{y}_{1}^{+}} \frac{\mathrm{dy}^{+}}{\left.\left.\frac{\varepsilon_{\nu}}{\nu \phi}+\left(\frac{\mathrm{du}^{+}}{\mathrm{dy}^{+}}\right)^{\mathrm{n}-1}\right\}\right]}
\end{gathered}
$$

Integrating equation (10) from the wall to the outer bound of the transition region and combining with equation (16):

$$
\begin{aligned}
& T_{\text {ave }}-T_{w}=\frac{q_{w} U_{\text {ave }}}{C_{p^{T} w}{ }^{T}}\left[1-\left(\frac{f}{2}\right)^{1 / 2}\left[\int_{0}^{y_{c}^{+}} \frac{d y^{+}}{\frac{\varepsilon_{\nu}}{\nu \phi}+\left(\frac{d U^{+}}{d y^{+}}\right)^{n-1}}\right.\right. \\
& \left.\left.+\int_{y_{c}^{+}}^{y_{1}^{+}} f_{1} \frac{d_{y^{+}}^{+}}{\frac{\varepsilon_{\nu}}{\nu \phi}+\left(\frac{d^{+}}{d y^{+}}\right)^{n-1}}\right]\right] \\
& +\frac{q_{w}}{\rho C_{\mathrm{P}} \mathrm{U}_{*}}\left[\int_{0}^{y_{c}^{+}} \frac{\mathrm{dy}^{+}}{\frac{1}{\mathrm{~N}_{\mathrm{Pr}}, \phi}+\frac{\varepsilon_{\mathrm{c}}}{\nu \phi}}+\int_{\mathrm{y}_{\mathrm{c}}^{+}}^{\mathrm{y}_{1}^{+}} \mathrm{f}_{1} \frac{\mathrm{dy}^{+}}{\frac{1}{\mathrm{~N}_{\mathrm{Pr}}, \phi}+\frac{{ }^{\prime} \mathrm{c}}{\nu \phi}}\right]
\end{aligned}
$$

Defining the Stanton number as follows:

$$
N_{S t}=\frac{q_{w}}{\rho C_{P} U_{\text {ave }}\left(T_{\text {ave }}-T_{w}\right)}
$$

and after rearrangement, the final equation becomes:

$$
\begin{aligned}
& N_{S t}=\frac{f / 2}{f_{2}} \\
& \text { where: } f_{2}=1+(\mathrm{f} / 2)^{1 / 2}\left[\int_{0}^{y_{c}^{+}} \frac{\mathrm{dy}^{+}}{\frac{1}{\mathrm{~N}_{\mathrm{Pr}}{ }^{+} \phi}+\frac{\varepsilon_{c}}{\nu \phi}} \cdot \int_{0}^{y_{c}^{+}} \frac{\mathrm{dy}^{+}}{\frac{\varepsilon_{\nu}}{\nu \phi}+\left(\frac{\mathrm{dU}^{+}}{\mathrm{dy}^{+}}\right)^{\mathrm{n}-1}}\right]
\end{aligned}
$$

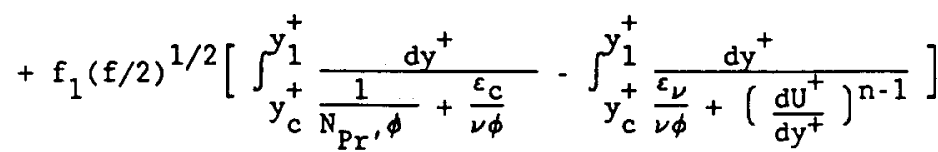


In order to evaluate the final equation, eddy and velocity distribution equations must be known. As such, the following Newtonian eddy and velocity distribution relationships were applied:

1. Wasan [10]

$\mathrm{y}^{+} \leq 20 \mathrm{u}^{+}=\mathrm{y}^{+}-1.04 \times 10^{-4}\left(\mathrm{y}^{+}\right)^{4}+3.03 \times 10^{-6}\left(\mathrm{y}^{+}\right)^{6}$

$$
\frac{\varepsilon}{\nu}=\frac{4.16 \times 10^{-4}\left(y^{+}\right)^{3}-15.15 \times 10^{-6}\left(y^{+}\right)^{4}}{1-4.16 \times 10^{-4}\left(y^{+}\right)^{3}+15.15 \times 10^{-6}\left(y^{+}\right)^{4}}
$$

2. Van Driest, E.R. [12]

$$
\begin{gathered}
\frac{\varepsilon}{\nu}=\left(\frac{y^{+}}{A}\right)^{2}\left\{1-\exp \left(-\frac{y^{+}}{C}\right)^{2}\right\} \frac{\partial U^{+}}{\partial y^{+}} \\
\frac{\partial U^{+}}{\partial y^{+}}=\frac{2}{1+\left\{1+4\left(y^{+} / A\right)^{2}\left(1-\exp \left(-y^{+} / C\right)\right)^{2}\right\}^{1 / 2}}
\end{gathered}
$$

Finally, the results were compared to the following correlations:

1. Metznet and Friend [5]

$$
\mathrm{N}_{S t}-\frac{\mathrm{f} / 2}{1.20+11.8(\mathrm{f} / 2)^{1 / 2}\left(\mathrm{~N}_{\mathrm{Pr}_{\mathrm{w}}}-1\right)^{-0.33}}
$$

2. Sandall et a1. [11]

$$
\mathrm{N}_{S t}=\frac{(\mathrm{f} / 2)^{1 / 2}}{12.527 \mathrm{~N}_{\mathrm{Pr}}^{2 / 3}+1.241 \ln \left(\mathrm{N}_{\mathrm{Pr}^{\prime}}\right)+\frac{2.78}{\mathrm{n}} \ln \left(\frac{\mathrm{N}_{\left.\mathrm{Re}^{\prime} \sqrt{(f} / 2\right)}}{90}\right.}
$$

3. Krantz and Wasan [9]

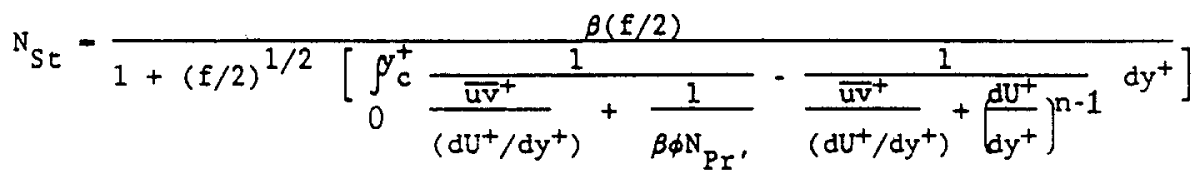

\section{Discussion}

Available heat transfer data sets $[2,13,14,15,16]$ for the turbulent flow of purely viscous, pseudoplastic fluids were used to verify different heat transfer correlations as well as the one proposed by the authors. In 
order to apply the heat transfer correlations of Metzner and Friend,

Sandall et al., Krantz and Wasan, and the one reported by the authors, it was necessary to determine the non-Newtonian friction factor, $f$, from the experimental data. One exception to this was the data reported by Clapp [2] for which case the friction factor was evaluated from the correlation of Dodge and Metzner.

For the purpose of comparison, the absolute percent arithmetic average deviation, $\delta$, and percent standard deviation, $\sigma$, were defined as follows:

$$
\begin{aligned}
& \delta=\left.\left.\left.\left.\frac{100}{N} \sum_{i=1}^{N}\right|^{{ }^{N} t_{\text {theo. }} \cdot{ }^{N_{S t}}}\right|_{i}\right|_{\text {exp. }}\right|_{\text {exp. }} \\
& \sigma=100\left\{\frac{1}{N-1} \sum_{i=1}^{N}\left[\frac{{ }^{N} t_{\text {theo. }}-{ }^{N}{ }^{N} \text { exp. }}{N_{S t}}\right]_{\text {exp. }}\right\}_{i}
\end{aligned}
$$

A comparison of our proposed correlation with those of Metzner and Friend, Sandall et al., Krantz and Wasan, and Yoo and hartnett shows a significant improvement in the absolute percent arithmetic average and the percent standard deviation as shown in Table (1).

TABLE 1

\begin{tabular}{|c|c|c|c|c|}
\hline \multicolumn{3}{|c|}{$\begin{array}{l}\text { Absolute Percent } \\
\text { Arithmetic Average } \\
\end{array}$} & \multicolumn{2}{|c|}{$\begin{array}{c}\text { Percent Standard } \\
\text { Deviation }\end{array}$} \\
\hline $\begin{array}{r}\text { All } \\
\text { clud. } \\
\text { so }\end{array}$ & $\begin{array}{l}\text { data in- } \\
\text { Attagel } \\
\text { lution }\end{array}$ & $\begin{array}{c}\text { Data exclud. } \\
\text { Attagel } \\
\text { solution }\end{array}$ & $\begin{array}{l}\text { All data in- } \\
\text { clud. Attagel } \\
\text { solution }\end{array}$ & $\begin{array}{l}\text { Data exclud. } \\
\text { Attagel } \\
\text { solution }\end{array}$ \\
\hline Metzner-Friend & 18.73 & 18.23 & 21.63 & 21.14 \\
\hline Krantz-Wasan & 49.06 & 45.22 & 50.85 & 46.87 \\
\hline Sandall et al. & 25.04 & 21.71 & 30.79 & 28.38 \\
\hline Yoo-Hartnett & 10.50 & 11.08 & 12.31 & 12.91 \\
\hline $\begin{array}{l}\text { Present model } \\
\text { incorporating }\end{array}$ & $\begin{array}{c}18.71 \\
\text { Wasan's }\end{array}$ & $\begin{array}{l}13.85 \\
\text { equation }\end{array}$ & 23.75 & 16.02 \\
\hline $\begin{array}{l}\text { Present model } \\
\text { incorporating }\end{array}$ & $\begin{array}{l}13.68 \\
\text { Van Drie }\end{array}$ & $\begin{aligned} & 7.65 \\
& \text { st's equation }\end{aligned}$ & 21.04 & 10.46 \\
\hline
\end{tabular}
Comparison Between Existing and Proposed Models

In case of Van Driest's distribution equations [12], one must determine the two constants, $A$ and $C$ in equation (23). Van Driest determined these constants from experimental data obtained for Newtonian fluids. He reported the following values: $A=2.50$ and $C=27.00$. In our case, these values had to be determined for non-Newtonian fluids as shown in Table (2). 
TABLE 2

Constant For Van Driest's Eddy Viscosity And Velocity Distribution

\begin{tabular}{|c|c|c|}
\hline & $\begin{array}{l}\text { Absolute Percent } \\
\text { Arithmetic Average }\end{array}$ & $\begin{array}{c}\text { Percent Standard } \\
\text { Deviation }\end{array}$ \\
\hline $\begin{array}{l}\text { Model } 1 \\
A=2.5, C=40.33\end{array}$ & 12.65 & 14.35 \\
\hline $\begin{array}{l}\text { Model } 2 \\
A=2.5, C=45.33\end{array}$ & 9.32 & 11.15 \\
\hline $\begin{array}{l}\text { Model } 3 \\
A=2.5, C=50.33\end{array}$ & 7.65 & 10.46 \\
\hline $\begin{array}{l}\text { Model } 4 \\
A=2.5, C=55.33\end{array}$ & 7.52 & 10.51 \\
\hline
\end{tabular}

As suggested by Bouge and Metzner [1], one may use the Newtonian velocity distribution for a non-Newtonian fluid providing that one normalizes the velocity with respect to the mean velocity. The universal constant, $A$, in this case was assumed to be equal to 2.50 i.e., the value reported for Newtonian fluids. The other constant was treated as a parameter in the proposed equation during the numerical integration. Our results showed that the value of $C$ could be either 50.33 or 55.33 as shown in Table (2). A value of 50.33 was selected due to its lowest percent standard deviation. Comparison of results with those reported by Metzner and Friend, Sandall et al., Krantz and Wasan and Yoo and Hartnett are shown in Figures 1 to 4 .

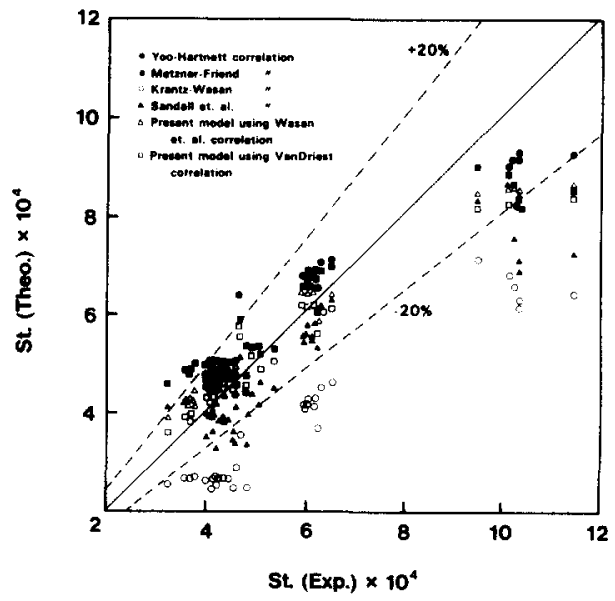

FIG. 1 Comparison between theo. and exp. $\mathrm{N}_{\mathrm{St}}, \mathrm{n}=0.81-0.92$; data from Yoo, Friend, and Farmer.

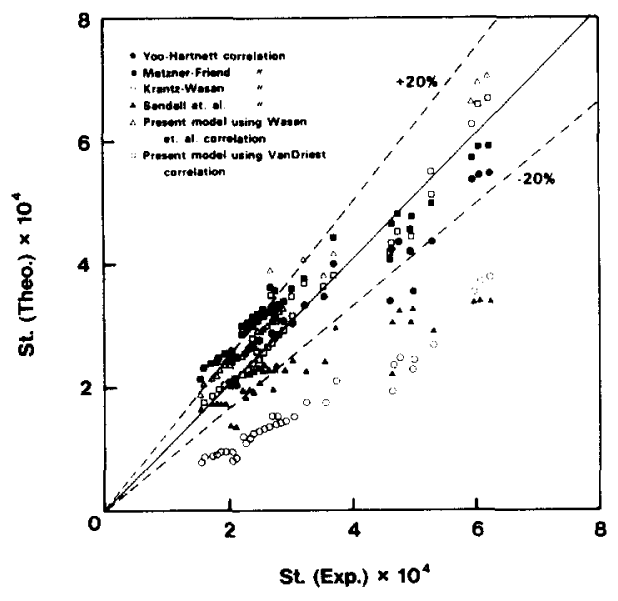

FIG. 2

Comparison between theo. and exp. $\mathrm{N}_{S t}, \mathrm{n}=0.65-0.786$, data from Yoo, clapp, Farmer and Haines. 


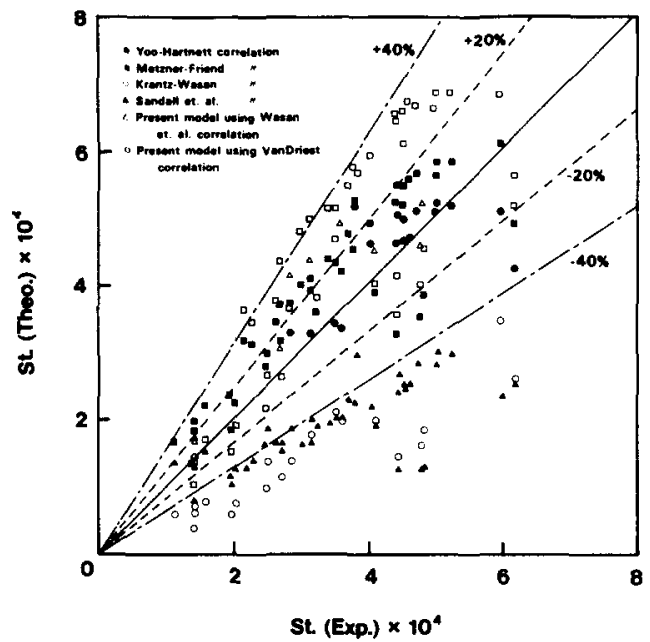

FIG. 3

Comparison between theo. and exp. $\mathrm{N}, \mathrm{n}=0.3040-0.6491$; data from Yoo, Friend, Farmer and Haines.

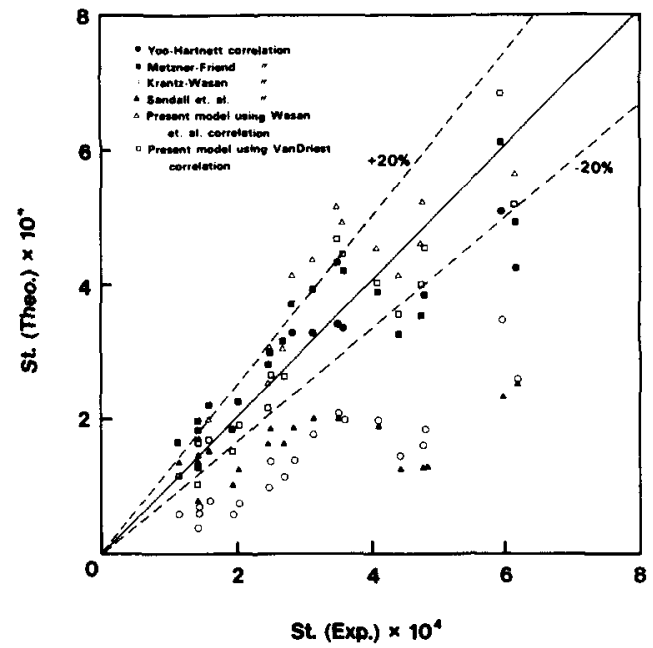

FIG. 4

Comparison between theo. and exp.

$\mathrm{N}_{\mathrm{St}}, \mathrm{n}=0.39-0.6491$; data from Yoo', Friend, Farmer and Haines.

As shown, in Figure 3, our proposed correlation fits the data more closely than the Krantz-Wasan relationship and is equally comparable with the correlation reported by Sandall et al. However, Metzner and Friend's correlation shows a better fit. It should be noted that Yoo and Hartnett's data includes Attagel solutions. If one eliminates Atta-gel solutions, then as shown in Figure 4, our proposed correlation shows a closer fit when compared with all the existing correlations. Furthermore, if one compares the existing correlations using all the available data, Table 1, and over a wide range of flow behavior index $(0.3<n<0.9)$, the proposed correlation shows the best absolute-percent-arithmetic-average and the best percent-standarddeviation when Van Driest's eddy and velocity distribution equation is used. In addition to the above, for the proposed correlation, the difference between the experimental and theoretical values are mostly within a range of \pm 208 except for data that include Attagel solutions, Figure 4 , where this range is extended to \pm 408 which is equally comparable with the other correlations. Furthermore, this correlation is applicable to both transitional and turbulent flow of pseudoplastic fluids. As such, there are no restrictions such as equation (3) for the case of Metzner and Friend's correlation or the Reynolds number restriction of the Yoo and Hartnett's correlation, equation ( 8 ). 


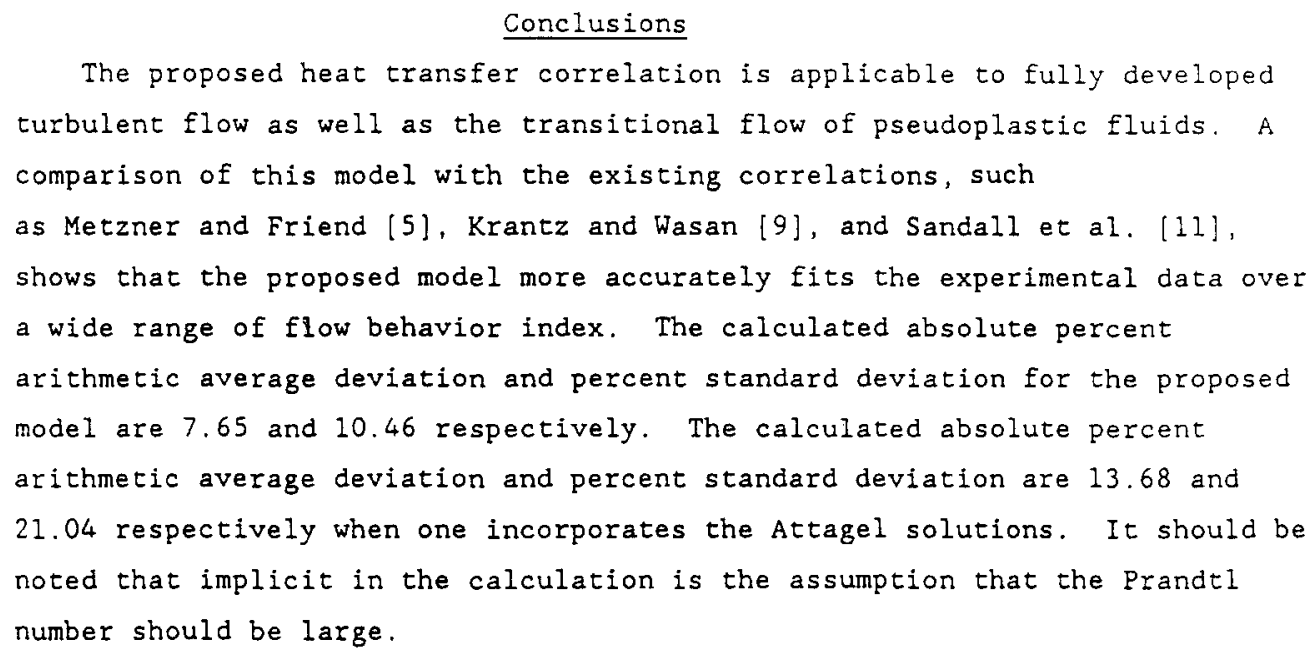

The proposed heat transfer correlation is applicable to fully developed turbulent flow as well as the transitional flow of pseudoplastic fluids. A comparison of this model with the existing correlations, such as Metzner and Friend [5], Krantz and Wasan [9], and Sandall et al. [11], shows that the proposed model more accurately fits the experimental data over a wide range of flow behavior index. The calculated absolute percent arithmetic average deviation and percent standard deviation for the proposed model are 7.65 and 10.46 respectively. The calculated absolute percent arithmetic average deviation and percent standard deviation are 13.68 and 21.04 respectively when one incorporates the Attagel solutions. It should be noted that implicit in the calculation is the assumption that the Prandt 1 number should be large.

\section{Nomenclature}

$\mathrm{C}_{\mathrm{p}} \quad$ Heat capacity at constant pressure, $\mathrm{kcal} . /(\mathrm{kg})\left({ }^{\circ} \mathrm{C}\right)$

D Pipe Radius, m.

f Fanning friction factor, dimensionless

$\mathrm{h}$ Heat transfer coefficient, kcal. $/\left(\mathrm{m}^{2}\right)(\mathrm{hr}).\left({ }^{\circ} \mathrm{C}\right)$

k Thermal conductivity, kcal./(m.)(hr. $\left({ }^{\circ} \mathrm{C}\right)$

$\mathrm{K} \quad$ Fluid consistency index

$\mathrm{n}, \mathrm{n}^{\prime} \quad$ Flow behavior index, dimensionless

$\mathrm{N}$ Number of experimental observations

$\mathrm{N}_{\mathrm{Nu}} \quad$ Nusselt number, $\frac{\mathrm{hD}}{\mathrm{k}}$

$\mathrm{N}_{\mathrm{Pr}}$, Generalized Prandtl number, $\nu \rho \mathrm{C}_{\mathrm{p}} / \mathrm{k}$

$\mathrm{N}_{\operatorname{Pr}} \quad$ Defined by equation (4)

$\mathrm{N}_{\mathrm{Pr}} \mathrm{C}$ Prandt 1 number at the wall

$\mathrm{N}_{\mathrm{Re}^{\prime}} \mathrm{Pr}_{\mathrm{w}} \quad$ Generalized Reynolds number, $\mathrm{DU}_{\text {ave }} / \nu$

$\mathrm{N}_{\text {St }} \quad$ Stanton, $\mathrm{h} / \mathrm{C}_{\mathrm{p}} \rho \mathrm{U}_{\text {ave }}$

$\mathrm{N}_{\text {St }} \quad$ Stanton number obtained from experiments

St exp. Stanton number obtained from a correlation

$\mathrm{q}$ ' theo. Heat flux, kcal./(m.) ${ }^{2}$ (hr.)

$q_{w} \quad$ Heat flux at the wall

$r \quad$ Radial coordinate, $m$.

$\mathrm{T}$ Temperature, ${ }^{\circ} \mathrm{C}$ 


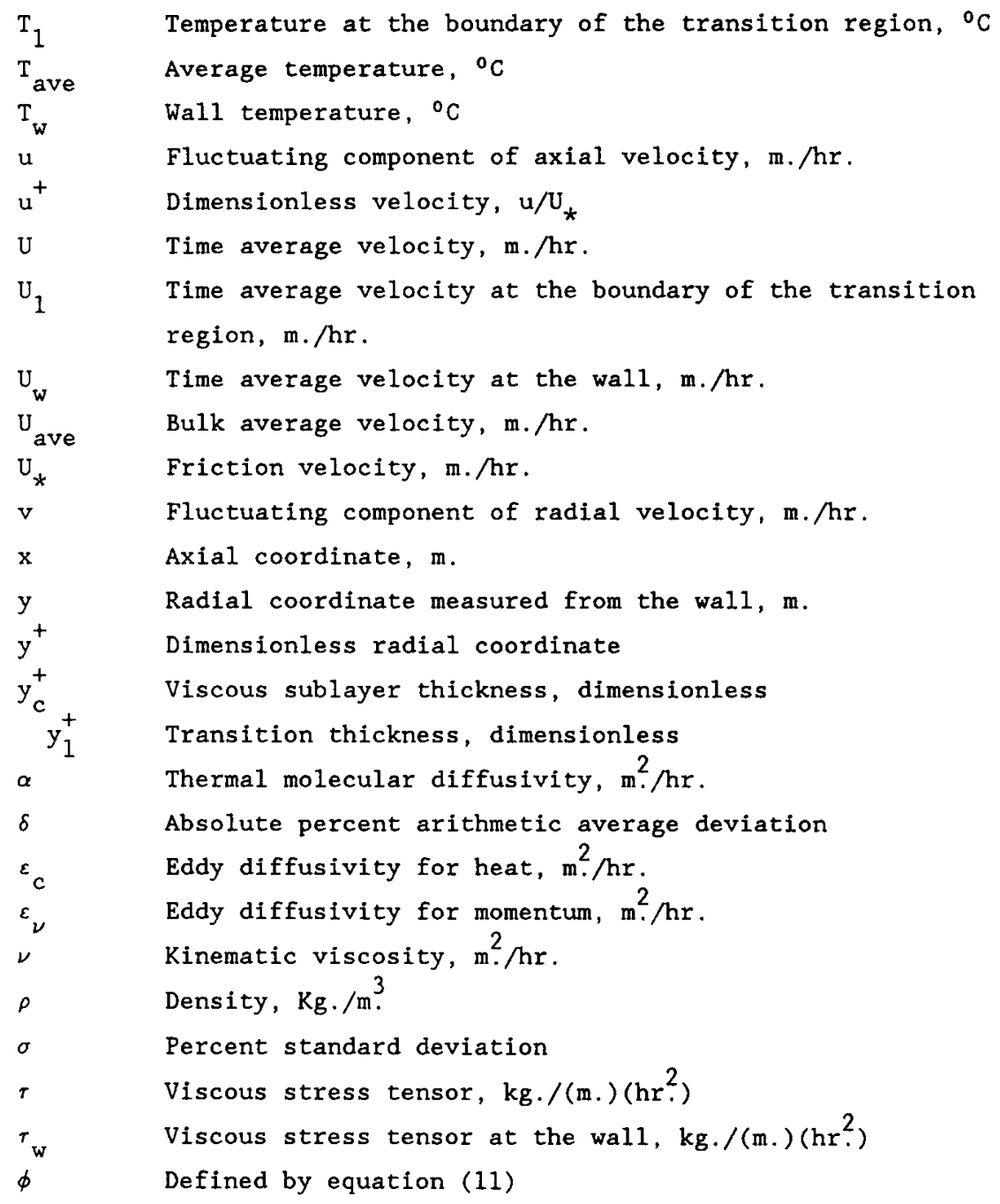

\section{$\underline{\text { References }}$}

1. D.C. Bouge and A.B. Metzner, Velocity Profile in Turbulent Pipe Flow, I.\&EC. Fund., 2, 143 (1963).

2. R.M. Clapp, Turbulent Heat Transfer in Pseudoplastic NonNewtonian Fluids, International Developments in Heat Transfer, ASME, p. 652, D211, New York (1963).

3. D.W. Dodge and A.B. Metzner, Turbulent Flow of Non-Newtonian Systems, AIChE Journal, 5, 189 (1959). 
4. C.B. Millikan, A Critical Discussion of Turbulent Flows in Channels and Circular Tubes, Proc. Fifth Int. Cong. for Appl. Mech., p. 386 (1939).

5. A.B. Metzner and P.S. Friend, Heat Transfer to Turbulent NonNewtonian Fluids, Ind. Eng. Chem. J., 51, 879 (1959).

6. A.W. Petersen and E.B. Christiansen, Heat Transfer to NonNewtonian Fluids in Transitional and Turbulent Flow, AIChE Journal, 12, 221 (1966).

7. S. Yoo and J.P. Hartnett, Heat Transfer and Friction Factors for Purely Viscous Non-Newtonian Fluids in Turbulent Pipe Flow, ASME, p. 218 (1974).

8. R. Smith and M.F. Edwards, Heat Transfer to Non-Newtonian and Drag-Reducing Fluids in Turbulent Pipe Flow, Int. J. Heat Mass Trans., 24, 1059 (1981).

9. W.B. Krantz and D.T. Wasan, Heat, Mass and Momentum Transfer Analogies for the Fully Developed Turbulent Flow of Power Law Fluids in Circular Tubes, AIChE J., 17, 1360 (1971).

10. D.T. Wasan, Theoretical Correlation of Velocity and Eddy Viscosity for Flow Close to a Pipe Wall, AIChE J., 9, 567 (1963).

11. Sanda11, Turbulent Non-Newtonian Transport in a Circular Tube, AIChE J., 22, 1142 (1976).

12. E.R. Van Driest, On Turbulent Flow Near a Wall, J. Aero. Sci., 23, 1007 , (1956).

13. R.C. Farmer, M.Ch.E. Thesis, University of Delaware (Data obtained from Friend (1958)).

14. P.S. Friend, M.Ch.E. Thesis, University of Delaware (1958).

15. R.C. Haines, B.Ch.E. Thesis, University of Delaware (1957), (Data obtained from Friend (1958)).

16. S. Yoo, Ph.D. Thesis, University of Illinois (1974). 